\title{
La divulgación radiofónica de la alimentación y la nutrición. El ejemplo de Radio 5 Todo Noticias
}

\author{
Ángela Bernabeu-Peiró \\ Periodista y máster en radio
}

\section{Palabras clave \\ Comunicación y salud Educación sanitaria Alimentación Nutrición Divulgación radiofónica Radio educativa Cápsulas informativas (quesitos) \\ Radio 5 Todo Noticias (1998-2013).}

Resumen

En un contexto donde los hábitos alimentarios de la población están dando señales de alarma y provocando problemas de malnutrición, sobrepeso y obesidad, el trabajo aborda el papel que pueden jugar los medios de comunicación y más concretamente la radio de titularidad pública, en la divulgación de conocimientos científicos relacionados con la alimentación y nutrición. Tras exponer el marco teórico de la comunicación para la salud donde cabe ubicar la función educativa de la radio, se analiza el desarrollo de la fórmula radiofónica de Radio 5 Todo Noticias y su experiencia en la divulgación de una alimentación y nutrición saludable. El análisis de las cápsulas temáticas 0 quesitos, la fórmula utilizada entre 2008 y 2013, ha permitido mostrar sus posibilidades en la popularización de dichos conocimientos y en la mejora de los hábitos alimentarios y la salud de la población. La importancia de la participación de los expertos en dicha experiencia, aconseja profundizar en la formulación de propuestas de colaboración entre los profesionales del periodismo y del ámbito sanitario, al igual que ocurre con la necesidad de introducir mejoras en las técnicas comunicativas que permitan ampliar los canales y los mecanismos de retroalimentación. 


\section{Radio broadcasts regarding food and nutrition. The example of Radio 5 Todo Noticias}

\begin{tabular}{l}
\hline Keywords \\
\hline Communication and health \\
Health education \\
Food \\
Nutrition \\
Radio divulgation \\
Educational radio \\
News break \\
Radio 5 Todo Noticias \\
(1998-2013).
\end{tabular}

Agradecimientos: A Consuelo López Nomdedeu, Teo Sánchez y Paloma Zamorano Martínez por su colaboración y la valiosa información que aportaron en sus entrevistas.

\section{Cómo citar el artículo}

Bernabeu-Peiró, A. (2015). La divulgación radiofónica de la alimentación y la nutrición. El ejemplo de Radio 5 Todo Noticias. Revista de Comunicación y Salud, Vol. 5, pp. 37-54.

DOI: http://doi.org/10.35669/revistadecomunicacionysalud.2015.5.37-54

\begin{abstract}
In a context where the population's eating habits are raising the alarm and causing problems regarding malnutrition, overweight and obesity, this report tackles the role that the media, in particular public service radio stations, may have in disseminating scientific knowledge related to food and nutrition. After explaining the theoretical framework of communication in which the communicative role of radio is highlighted, the development of broadcasting methods of Radio 5 Todo Noticias and its experience in disseminating healthy food and nutritional habits are analyzed. The analysis of the themed news break, the method used between 2008 and 2013, allowed to prove its possibilities in the popularization of such knowledge and in the improvement of the population's eating habits and health. The importance of experts involved in such experience advise to delve into formulating collaboration proposals among professionals in the fields of journalism and health, as is also the case with the need of introducing new improvements in communicative techniques, which will allow to broaden feedback channels and mechanisms.
\end{abstract}




\section{Introducción}

Los hábitos alimentarios de la población española son inadecuados y están ocasionando malnutrición y problemas de salud como sobrepeso y obesidad, tal como se recoge en el Libro Blanco de la Nutrición en España (Varela, ed., 2013). En la última encuesta publicada por la Agencia Española de Consumo, Seguridad Alimentaria y Nutrición (AECOSAN) (Presentación de la Encuesta Nacional de Ingesta Dietética Española, 2012) el patrón de consumo era contrario a lo que recomienda la pirámide de la Dieta Mediterránea.

Para poder mejorar dichos hábitos, la educación en materia de alimentación y nutrición resulta fundamental. Los medios de comunicación de masas y la radio en particular, pueden ayudar en dicha tarea y mejorar el empoderamiento de la población. En este contexto, la radio de titularidad pública está llamada a jugar un papel destacado. Parece oportuno evaluar iniciativas como las que se han llevado a cabo en España en materia de educación en alimentación y nutrición a través del medio radiofónico, y en concreto, la de Radio 5 Todo Noticias a través de la fórmula de las cápsulas temáticas conocidas popularmente como quesitos y su continuidad en programas como el de 'Alimento y salud'.

El presente trabajo, trata de realizar una valoración crítica de dicha experiencia, con el objeto de analizar las posibilidades que ofrece el medio radiofónico para informar y educar en materia de salud, así como las estrategias de comunicación que ayuden a alcanzar estos objetivos.

\subsection{Comunicación y salud: la función educativa de la radio}

De forma paralela al interés que suscitan entre la población las cuestiones relacionadas con la salud, la comunicación social ha adquirido un papel relevante en el abordaje de los retos sanitarios que tienen planteados las sociedades contemporáneas. Las informaciones sobre salud que proporcionan los medios de comunicación se han convertido en un referente para los procesos de búsqueda de la salud (De Semir, 2003: 5; Menéndez, 2008: 10; Perelló, Muela, 2011; López Nomdedeu, 2012: 102; Camacho, Peñafiel, Ronco, 2012).

En atención a su trascendencia, los profesionales de la comunicación están obligados a facilitar la promoción del conocimiento social de la salud y la enfermedad y a manejar las informaciones relacionadas con estas temáticas, con rigor y calidad, pero sin olvidar su comprensibilidad (González Huesa, 2008: 13-16).

A través de la información se puede y se debe contribuir a la educación y la promoción para la salud. El uso adecuado de los medios informativos favorece el proceso de comunicación en salud y contribuye al empoderamiento sanitario de los individuos y las comunidades (Díaz, Uranga, 2011; González Huesa, 2008: 70-71; López Nomdedeu, 2012: 103).

Además de informar y distraer a las audiencias, los medios de comunicación también tienen la responsabilidad social de contribuir a su educación e influir en la modificación de los conocimientos, las actitudes y los hábitos de la población en materia de salud siempre que alcancen el grado adecuado de credibilidad (López Nomdedeu, Lobato, s.f.: 3-5; González Conde, 2000: 142; Sánchez Martos, 2008: 81-82).

Para conseguir dicha credibilidad, la colaboración entre los periodistas y los profesionales de salud puede resultar muy útil. Estos últimos dominan los contenidos de los mensajes que necesita conocer la población, mientras los profesionales de la comunicación controlan los medios y las técnicas para transmitirlos de forma atractiva y eficaz (Revuelta, 2006: 203; Martín Algarra, 2008: 166-167; Sánchez Martos, 2008: 83-84; Ugarte, 2008: 45-46; Alzate, 2013: 25). 
Para hacer frente al reto que supone que los medios de comunicación, y entre ellos la radio, se hayan convertido en una de las principales fuentes de información en materia sanitaria, además de fomentar una cultura mediática que ayude a interpretar críticamente las informaciones transmitidas desde los media, hay que evitar que la audiencia se convierta en un receptor pasivo del mensaje y conseguir una retroalimentación bidireccional de la información. Es necesario elaborar y transmitir un mensaje que sea claro, relevante, sencillo, bien estructurado y que asegure el feedback con el objeto de poder comprobar su comprensión (López Nomdedeu, Lobato, s.f.: 6-8; Huertas, Gutiérrez, 2006: 59-62; Alonso, 2008: 75; Cuesta, Menéndez, García Guardia, 2008: 37; Espeitx, Cáceres, 2008: 171-172; Sánchez Martos, 2008: 82-83).

El medio radiofónico por su inmediatez, por la sencillez en la producción de contenidos y por facilitar la interacción con la audiencia, se muestra como una alternativa adecuada para la comunicación en salud, aunque no esté exenta de dificultades (González Conde, 2000: 132-144; Legorburu, 2001: 143-156; Gómez, 2002: 60-64; Huertas, Gutiérrez, 2006; Rodero, 2008; Roldán, 2009). A la heterogeneidad de la audiencia, se une el reto de compaginar información y distracción o asegurar frente a la rapidez de su emisión, el rigor, la comprensión y la retención de los conceptos más relevantes (González Conde, 2000: 151-152).

\subsection{El desarrollo de la fórmula radiofónica de Radio 5 Todo Noticias}

El 18 de abril de 1994 nacía Radio 5 Todo Noticias y se ponía en marcha la primera emisión española de cobertura nacional dedicada exclusivamente a la información. Abordaba todos los géneros periodísticos, a excepción del de la opinión (Chomón, 2010: 205-208; 2011: 194-242).

La aparición de la fórmula Radio 5 Todo Noticias potenció la vertiente de servicio público de Radio 5 (González Conde, 2000: 446-448).Se emitían diversos espacios divulgativosen los que se abordaban cuestiones relacionadas con la ciencia, el medio ambiente o la salud, y que reunían la condición en muchas ocasiones de "píldoras informativas" (Chomón Serna, 2011: 223). La fórmula de Radio 5 Todo Noticias formaría parte de las radios especializadas que participan del concepto de radioinformación-comunicación (Moreno, 2005: 69-80).

La programación de Radio 5 Todo Noticias "no ha sido estable y ha sufrido cambios de manera constante" (Chomón Serna (2011: 243). Como se recoge en la web de RTVE (http://participaradio5.rtve.es/), durante la etapa de Manuel Ventero al frente de Radio 5 (2012-2013) se creó un canal para aunar las redes sociales, la participación ciudadana y la radio. Lo llamaron Radio 5.0 y le añadieron el subtítulo "Crea y comparte tus audios". Cualquier ciudadano podía subir sus contenidos de audio (podcast) sobre sus temas y asuntos preferidos y estos podían ser emitidos por Radio 5. La idea fue muy bien acogida y de hecho, se registraron numerosos participantes que fueron subiendo poco a poco sus podcast.

En abril de 2013, coincidiendo con el final del período objeto de estudio de este trabajo (Web de RTVE [http://participaradio5.rtve.es/]), Pedro Antonio Carreño Zapero fue nombrado director de Radio 5 y se suprimieron muchas de las capsulas informativas que habían servido para divulgar, entre otros contenidos, cuestiones relacionadas con la salud.

\subsection{La divulgación radiofónica de la alimentación y la nutrición en Radio 5 Todo Noticias}

De acuerdo con la información trasladada por la que fuera jefa de programas de Radio 
5 Todo Noticias, Paloma Zamorano Martínez (Comunicación personal, 25 de marzo de 2014), fue en 1998 cuando se contó, por primera vez, con una sección dedicada a nutrición y a educación alimentaria que reunía la condición de cápsula informativa o quesito, con el objeto de informar, divulgar y concienciar al oyente: "Se trataba de una serie de programas o micro-espacios, de entre 3 y 5 minutos, que se les llamaba quesitos por la similitud con las piezas del juego del trivial que salió por aquella época".

En relación con los criterios que se seguían para elegir las temáticas que se divulgaban, Paloma Zamorano (Comunicación personal, 25 de marzo de 2014) señala que, en general, estaban relacionados con la actualidad y solía ser el autor de cada quesito quien determinaba su contenido. En otras ocasiones eran los oyentes los que sugerían o pedían un tema.

Los expertos encargados de preparar los mini-espacios solían ser personas que colaboraban con alguna de las emisoras de RNE o profesionales de prestigio con los que se había tenido algún contacto.

Las cápsulas informativas eran grabadas y locutadas por los expertos. Como explica Consuelo López Nomdedeu (Comunicación personal, 13 de marzo de 2014), especialista en Educación Nutricional y profesora de Educación para la Salud de la Escuela Nacional de Sanidad (Instituto de Salud Carlos III), quien colaboró en la preparación y locución de quesitos entre 2001 y 2006, su objetivo era el de divulgar adecuadamente los conceptos relacionados con la alimentación, pero siempre desde la perspectiva más comunitaria de la salud pública y no desde las enfermedades asociadas a la nutrición (Trescastro López, et al, 2015: 30-34). El criterio que seguía para elegir la temática objeto de divulgación era su "buen saber y entender", observando lo que ocurría a su alrededor e intentando abordar cuestiones que podían interesar a la gente de la calle, además de realizar un seguimiento de la prensa y de las novedades relacionadas con la alimentación y la nutrición. Si salía al mercado un alimento servicio, como la tortilla de patata congelada y lista para consumir, con un lenguaje lo más coloquial posible exponía sus ventajas, sus inconvenientes, la relación calidad-costo, si merecía o no la pena en función del tiempo disponible, etc.

Consuelo López Nomdedeu (Comunicación personal, 13 de marzo de 2014) destacaba la dificultad para encontrar una manera sencilla y atractiva de dirigirse a la gente y que no resultase monótona. Al no conocer la audiencia a la que se dirigía, resultaba complicado encontrar el lenguaje adecuado. Aunque reconoce que los sanitarios no suelen tener la preparación adecuada y manifiestan muchas resistencias para participar en los medios, en su opinión, se trata de un error y "no se puede renunciar a un recurso tan valiosísimo", sobre todo cuando además se les ofrece la oportunidad de intervenir en un medio creíble y libre, como el que debería representar la radio pública.

Para reforzar la credibilidad de la información transmitida con los quesitos, además de la referencia obligada a Radio 5 Todo Noticias, López Nomdedeu (Comunicación personal, 13 de marzo de 2014) solía introducir su filiación o su especialidad: "para la audiencia es muy importante la fiabilidad de la fuente". También insistía en que reforzaba dicha confianza el hecho de ser emitido el mensaje desde una radio pública (Huertas, Gutiérrez, 2006: 57-58).

Respecto a la existencia de un posible feedback con la audiencia, Paloma Zamorano Martínez (Comunicación personal, 25 de marzo de 2014) explica que desde el principio se contaba con un contestador automático para recoger las consultas 0 sugerencias de los oyentes. Se trataba de una técnica comunicativa que ha tenido 
continuidad con la aparición de Internet y una mayor participación a través de las redes sociales: Twitter y Facebook.

Para Paloma Zamorano (Comunicación personal, 25 de marzo de 2014), la divulgación científica en general, y la relacionada con la salud, la alimentación y la nutrición, en particular, forman parte de la "esencia" de Radio 5 Todo Noticias, y responde al objetivo de conseguir que el oyente, además de entretenido, este informado.

Tras esta primera etapa de divulgación de la alimentación y nutrición que se había iniciado, como se ha indicado, en 1998, en mayo de 2008 se iniciaba una segunda etapa a través de la difusión de los mini-espacios que conformaban el programa 'Alimento y salud', objeto principal del presente trabajo. En torno a esa misma fecha, octubre de 2008, empezó a emitirse en Radio 5 Todo Noticias el programa 'A su salud', con un formato similar de cápsulas informativas de una duración de entre 4 y 6 minutos (http://www.rtve.es/alacarta/audios/a-su-salud/).

\section{Objetivos e hipótesis de investigación}

El objetivo general de la investigación es analizar la divulgación sobre alimentación y nutrición desarrollada por Radio 5 Todo Noticias y como objetivos específicos se han planteado, en primer lugar, examinar desde un punto de vista periodístico los contenidos del programa 'Alimento y salud' emitidos entre mayo de 2008 y mayo de 2013 (disponibles en la web de RTVE). En segundo lugar, realizar un análisis documental de cápsulas informativas divulgadas en dicho espacio. En tercer lugar, completar la información disponible mediante testimonios de algunos de los protagonistas que participaron o participan en la experiencia divulgativa objeto de este análisis. Y por último, a partir de los resultados obtenidos, establecer recomendaciones que puedan ayudar a mejorar la divulgación de los conocimientos científicos sobre alimentación y nutrición y los hábitos alimentarios de la población a través del medio radiofónico.

La hipótesis de trabajo plantea las posibilidades de la fórmula radiofónica utilizada por Radio 5 Todo Noticias, para divulgar conocimientos científicos relacionados con la alimentación y la nutrición, y mejorar los hábitos alimentarios y la salud de la población.

\section{Metodología de investigación}

La metodología utilizada combina el enfoque cualitativo y cuantitativo. Se realizó una búsqueda bibliográfica de trabajos relacionados con la divulgación radiofónica de la alimentación y nutrición, a través de un perfil que contenía los descriptores divulgación radiofónica, radio educativa, medios de comunicación y salud, salud y radio, Radio 5 y Radio 5 Todo Noticias.

Junto a la información proporcionada por la bibliografía secundaria, se ha entrevistado a Paloma Zamorano Martínez (Comunicación personal, 25 de marzo de 2014), quien fuera jefa de Programas de Radio 5 Todo Noticias y a Consuelo López Nomdedeu (Comunicación personal, 13 de marzo de 2014), experta en educación nutricional y, como se ha indicado, colaboradora de Radio 5 Todo Noticias entre 2001 y 2006.

Para poder analizar los contenidos que se divulgaron en el espacio radiofónico 'Alimento y salud', además de entrevistar al director del programa, Teo Sánchez (Comunicación personal, 13 de mayo de 2014), se creó una base de datos -con el programa Excel para Windows XP- con los 367 quesitos que fueron emitidos entre 
mayo de 2008 y mayo de 2013 y que están disponibles en la página web de RTVE (http://www.rtve.es/alacarta/audios/alimento-y-salud/).

Tras el análisis documental de las cápsulas informativas se incorporó, de cada una de ellas, el título, la fecha de emisión, la duración y las palabras clave obtenidas tras la lectura y análisis del título y el resumen. Se realizó un análisis descriptivo básico distribución por temáticas y duración de los quesitos- y se procedió a agrupar los 367 mini-espacios en 6 grupos temáticos: alimentos, nutrientes, aspectos psicosociales de la alimentación, educación nutricional, seguridad alimentaria y tecnología de los alimentos y alimentación sana y ecológica.

Para analizar el lenguaje radiofónico empleado, la estructura de las cápsulas temáticas, la estrategia divulgativa o el público al que van dirigidas, tras escuchar los 367 quesitos, se procedió a un análisis detallado de una muestra aleatoria de 25 -uno de cada 15-.

\section{Resultados y discusión}

En relación a las temáticas sobre alimentación y nutrición que fueron objeto de divulgación entre 2008 y 2013 en el programa 'Alimento y salud' (véase tabla 1), las cuestiones relacionadas con los alimentos, en un sentido genérico, seguidas de la seguridad alimentaria y la tecnología de los alimentos, con un 25,3 y un 21,5\%, respectivamente, monopolizaron la mayoría de las cápsulas informativas del programa. La educación nutricional $(20,1 \%)$, los aspectos psicosociales de la alimentación -con un protagonismo destacado de los problemas asociados al sobrepeso, la obesidad y las dietas milagro (13,3\%), los nutrientes y la alimentación sana y ecológica -donde se incluyen también asuntos polémicos como la presencia de sustancias químicas en los alimentos o la problemática de los transgénicos (7,6\%), agrupan al resto de las cápsulas informativas.

De acuerdo con el testimonio del director y presentador del programa, Teo Sánchez (Comunicación personal, 13 de mayo de 2014), el criterio que se utilizó para elegir las temáticas divulgadas solía estar relacionado con la actualidad, aunque no fuera ese el objetivo del programa. Así mismo, de acuerdo con las recomendaciones que deben guiar la práctica periodística de divulgación de los temas de salud en el medio radiofónico (Huertas, Gutiérrez, 2006: 56), junto al desarrollo de contenidos más técnicos, se intentaban incorporar otros más amenos como los relacionados "con la cocina, con anécdotas, historia de la alimentación, etc.". Uno de los ejes principales del programa, en el formato en el que se emitía entre 2008 y 2013, era divulgar todos aquellos asuntos relacionados con el alimento desde todos los prismas posibles, pero con una mirada específica hacia los temas de salud pública.

Los contenidos del espacio 'Alimento y salud' no iban dirigidos a un público en concreto sino que estaban pensados para el público en general. Para la elaboración de los mismos, con el objeto de asegurar la credibilidad del mensaje que exige la divulgación de estas temáticas (Sánchez Martos, 2008: 83; López Nomdedeu, 2012: 103), se empleaban fuentes fiables y rigurosas con el fin de proporcionar seguridad al receptor, algo que resulta fundamental, como matiza Teo Sánchez (Comunicación personal, 13 de mayo de 2014), si tenemos en cuenta que de lo que se está hablando es de un tema tan serio como el de la salud. Algunas de las fuentes que refiere el director del programa eran: la Organización Mundial de la Salud (OMS), la Sociedad Española de Dietética y Ciencias de la Alimentación (SEDCA), la Organización de Naciones Unidas para la Agricultura y Alimentación (FAO), entre otras.

Respecto a la relación que debe existir entre el periodista y el experto a la hora de 
elaborar y divulgar los contenidos sobre salud, de acuerdo con lo que sostienen autores como Gemma Revuelta (2006: 203), Jesús Sánchez Martos (2008: 83-84) o José Manuel González Huesa (2008: 16), Teo Sánchez (Comunicación personal, 13 de mayo de 2014) mantiene que debe ser el experto "quien explique el tema a tratar" y que en su caso se da una doble circunstancia, a su condición de divulgador por su formación como veterinario y como conocedor de los temas relacionados con la alimentación, se suma su condición de informador.

Hay que indicar, sin embargo, que al pasar del formato de capsulas informativas de 35 minutos de duración, al formato de programa semanal de media hora de duración que tuvo lugar en 2013, Teo Sánchez (Comunicación personal, 13 de mayo de 2014) en lugar de utilizar únicamente su doble condición de divulgador e informador, ha incorporado al experto para que explique el tema a tratar. En su opinión, la figura del experto es fundamental a la hora de divulgar, y habría que aprovechar el interés que existe por parte de la comunidad científica de dar a conocer su trabajo.

Tabla 1. Relación de las cápsulas informativas o quesitos emitidos entre mayo de 2008 y mayo de 2013, agrupados por temáticas y por orden de aparición 


\begin{tabular}{|c|c|c|c|}
\hline $\begin{array}{l}\text { GRUPO 1: } \\
\text { ALIMENTOS (93 } \\
\text { quesitos, 25,3\% } \\
\text { del total de los } \\
\text { emitidos) }\end{array}$ & $\begin{array}{l}\text { Las propiedades } \\
\text { antioxidantes } \\
\text { de la cebolla } \\
\text { Las acelgas, } \\
\text { vitaminas } \\
\text { Los beneficios del } \\
\text { yogur } \\
\text { El poder del } \\
\text { espárrago } \\
\text { La aceituna, } \\
\text { guardiana del } \\
\text { corazón } \\
\text { Las cerezas } \\
\text { Pescado y } \\
\text { sucedáneos } \\
\text { La cerveza } \\
\text { Bebidas fermentadas } \\
\text { Los mejillones } \\
\text { La tónica } \\
\text { La leche } \\
\text { El brócoli } \\
\text { En torno a la cerveza } \\
\text { sin alcohol } \\
\text { El jamón serrano } \\
\text { El consumo de } \\
\text { pescado } \\
\text { Pan integral } \\
\text { La remolacha } \\
\text { Pescado del futuro } \\
\text { Salchichas } \\
\text { Chocolate y } \\
\text { flavonoides } \\
\text { El ajo y sus } \\
\text { virtudes }{ }^{22 / 02 / 10} \\
\text { Queso de leche } \\
\text { materna } \\
\text { La fresa } \\
\text { La chufa } \\
\text { Flores } \\
\text { comestibles }{ }^{\star 25 / 04 / 10 ~} \\
\text { Leche de avena } \\
\text { ¿Son tan buenas las } \\
\text { Bayas de Goji? } \\
\text { Más patatas } \\
\text { Seitán } \\
\text { Frutos secos } \\
\text { al }\end{array}$ & $\begin{array}{l}\text { Aceite de oliva } \\
\text { El pimiento } \\
\text { Sushi } \\
\text { La patata } \\
\text { El krill } \\
\text { La nueva lenteja } \\
\text { El marujito }{ }^{*} / 01 / 2011 \\
\text { La taurina } \\
\text { Atún en lata } \\
\text { El kéfir } \\
\text { Caracoles } \\
\text { Helado 'Babygaga' } \\
\text { Leche fresca'1/03/11 } \\
\text { Bebidas isotónicas } \\
\text { XXVI Feria de } \\
\text { quesos de } \\
\text { Trujillo } \\
\text { Leche } \\
\text { Melocotones } \\
\text { El pepino } \\
\text { Beber agua } \\
\text { Zumos en Europa } \\
\text { El gazpacho } \\
\text { Té } \\
\text { Patata e } \\
\text { hipertensión } \\
\text { Brócoli } \\
\text { Setas } \\
\text { Naranjas y } \\
\text { mandarinas } \\
\text { La calabaza } \\
\text { Fresas protectoras } \\
\text { Consumo de pan } \\
\text { Torta del Casar } \\
\text { Comer pescado } \\
\text { Queso Arzúa-Ulloa } \\
\text { Cabrales } \\
\text { Aceitunas } \\
\text { Té verde } \\
\text { Queso Majorero } \\
\text { Vainilla } \\
\text { taras }\end{array}$ & $\begin{array}{l}\text { Pescado blanco, } \\
\text { pescado azul } \\
\text { Atún de } \\
\text { almadraba }{ }^{* 28 / 04 / 12} \\
\text { Espárragostriguero } \\
\text { s } \\
\text { Queso de Mahón } \\
\text { Gazpacho } \\
\text { Dentro de un } \\
\text { refresco } \\
\text { El queso de Murcia } \\
\text { Pistacho y salud } \\
\text { Los refrescos } \\
\text { contra las cuerdas } \\
\text { No todos los } \\
\text { huevos son iguales } \\
\text { Sushi } \\
\text { La leche } \\
\text { Tipos de leche } \\
\text { Leche sí o no } \\
\text { Aceites } \\
\text { Oreja de mar } \\
\text { Plátanos de } \\
\text { Canarias } \\
\text { El queso más caro } \\
\text { del mundo } \\
\text { Cordero } \\
\text { El pomelo y sus } \\
\text { beneficios } \\
\text { Fresas y arándanos } \\
\text { para el corazón } \\
\text { Buey de Kobe } \\
\text { Queso Roncal } \\
\text { Ovoproductos }\end{array}$ \\
\hline
\end{tabular}




\begin{tabular}{|c|c|c|c|}
\hline $\begin{array}{l}\text { GRUPO 2: } \\
\text { NUTRIENTES (44 } \\
\text { quesitos, } 11,9 \% \\
\text { del total de los } \\
\text { emitidos) }\end{array}$ & $\begin{array}{l}\text { Oro y plata } \\
\text { comestibles } \\
\text { Descubrimiento } \\
\text { vitaminas } \\
\text { Sustitutos de las } \\
\text { grasas } \\
\text { Déficit de vitamina D } \\
\text { La stevia } \\
\text { El gomasio }{ }^{* 20 / 06 / 10} \\
\text { Importancia de los } \\
\text { carbohidratos } \\
\text { Las semillas } \\
\text { El sodio } \\
\text { Comer } \\
\text { insectos }{ }^{* 31 / 10 / 10} \\
\text { Antioxidantes } \\
\text { naturales } \\
\text { Descubrimiento } \\
\text { sobre las calorías } \\
\text { Alfacarotenos } \\
\text { Calcio } \\
\text { Importancia de la } \\
\text { vitamina C } \\
\text { El azafrán }\end{array}$ & $\begin{array}{l}\text { Ketchup y } \\
\text { prevención } \\
\text { La saliva } \\
\text { Aceite de pescado } \\
\text { Ácido linoleico } \\
\text { conjugado } \\
\text { Sal moderna } \\
\text { Calcio y } \\
\text { osteoporosis } \\
\text { Grasas trans } \\
\text { Aceite de oliva y } \\
\text { cáncer } \\
\text { Vino y colesterol } \\
\text { Crustáceos y } \\
\text { cadmio } \\
\text { Chicle } \\
\text { Carencia de } \\
\text { vitaminas } \\
\text { Sacarina }{ }^{*} 07 / 01 / 2012 \\
\text { Vitamina D y } \\
\text { gestación } \\
\text { Omega } 3 \text { y tabaco }\end{array}$ & $\begin{array}{l}\text { Calóricos pero } \\
\text { saludables } \\
\text { Nutrientes } \\
\text { esenciales } \\
\text { Aceite de oliva } \\
\text { monovarietal } \\
\text { Magnesio } \\
\text { ¿Superalimentos? } \\
\text { Vitaminas en } \\
\text { equilibrio } \\
\text { Nueva clara } \\
\text { Sodio y potasio } \\
\text { Vitamina D, más } \\
\text { que una vitamina } \\
\text { La fibra } \\
\text { Lúpulo } \\
\text { Biotina } \\
\text { Magnesio }\end{array}$ \\
\hline
\end{tabular}




\begin{tabular}{|c|c|c|c|}
\hline $\begin{array}{l}\text { GRUPO 3: } \\
\text { ASCPECTOS } \\
\text { PSICOSOCIALES } \\
\text { DE LA } \\
\text { ALIMENTACIÓN } \\
\text { (49 quesitos, } \\
13,3 \% \text { del total de } \\
\text { los emitidos) }\end{array}$ & $\begin{array}{l}\text { Estar a dieta no } \\
\text { resulta caro } \\
\text { Alimentos } \\
\text { afrodisíacos }{ }^{* 29 / 06 / 09} \\
\text { Alimentos bajos en } \\
\text { calorías } \\
\text { Autocontrol } \\
\text { publicidad infantil } \\
\text { Dieta para el verano } \\
\text { Afrodisiacos } \\
\text { El verano } \\
\text { Jóvenes y trastornos } \\
\text { alimentarios } \\
\text { El hambre mejora la } \\
\text { concentración } \\
\text { Compra de comida } \\
\text { en Internet } \\
\text { Cazadores de } \\
\text { tendencias } \\
\text { alimentarias } \\
\text { Sabor Umami } \\
\text { Kilos de más } \\
\text { Remedios en } \\
\text { Internet } \\
\text { Obesidad } \\
\text { ¿Contagiosa? } \\
\text { Publicidad de los } \\
\text { alimentos } \\
\text { España quiere } \\
\text { adelgazar } \\
\text { Jalea primaveral } \\
\text { La tartera del cole } \\
\end{array}$ & $\begin{array}{l}\text { Impuestos contra el } \\
\text { sobrepeso } \\
\text { Otoño } \\
\text { gastronómico*01/10/12 } \\
\text { Algas estimulantes } \\
\text { ¡Qué inventos! } \\
\text { Impuestos contra el } \\
\text { sobrepeso } \\
\text { Regulación } \\
\text { intestinal } \\
\text { Crisis y consumo } \\
\text { Alimentos } \\
\text { funcionales pero } \\
\text { ricos } \\
\text { Crisis y obesidad } \\
\text { Desayuno español } \\
\text { Ozono y } \\
\text { conservación } \\
\text { Obesidad y sexo } \\
\text { Dinamarca: } \\
\text { impuesto a grasas } \\
\text { Impuesto contra la } \\
\text { obesidad } \\
\text { Sobrepeso en } \\
\text { Japón Algunas } \\
\text { dietas milagro } \\
\text { Alimentos } \\
\text { afrodisíacos } \\
\text { Aumento de } \\
\text { obesidad en España }\end{array}$ & $\begin{array}{l}\text { La comida de las } \\
\text { madres } \\
\text { Dieta personalizada } \\
\text { Cafeína y agilidad } \\
\text { mental }{ }^{* 1 / 08 / 13} \\
\text { Nutrición } \\
\text { ortomolecular } \\
\text { El precio de los } \\
\text { huevos } \\
\text { Frutas con } \\
\text { denominación de } \\
\text { origen } \\
\text { Alimentos sin } \\
\text { milagros } \\
\text { No hay milagros } \\
\text { IVA y dieta } \\
\text { Saciarse } \\
\text { Crisis y obesidad } \\
\text { Máquinas de } \\
\text { comida }\end{array}$ \\
\hline
\end{tabular}




\begin{tabular}{|c|c|c|c|}
\hline $\begin{array}{l}\text { GRUPO 4: } \\
\text { EDUCACIÓN } \\
\text { NUTRICIONAL } \\
\text { (74 quesitos, } \\
20,1 \% \text { del total de } \\
\text { los emitidos) }\end{array}$ & $\begin{array}{l}\text { Resistencia a } \\
\text { insulina }{ }^{* 1 / 06 / 08} \\
\text { Comer con menos } \\
\text { sal } \\
\text { Motivos para } \\
\text { pasarse a los } \\
\text { desnatados } \\
\text { Consejos para } \\
\text { comer fuera de casa } \\
\text { Obesidad en las } \\
\text { escuelas } \\
\text { Dieta madres } \\
\text { lactantes } \\
\text { Plan reducción } \\
\text { consumo de sal } \\
\text { Comer despacio } \\
\text { Desayuno para niños } \\
\text { Ingredientes del } \\
\text { menú } \\
\text { Dieta mediterránea } \\
\text { Pirámide nutricional } \\
\text { Sistema } \\
\text { inmunológico y } \\
\text { alimentación }{ }^{* 30 / 10 / 09} \\
\text { Dieta antitabaco } \\
\text { Consumo de sal } \\
\text { Proyecto Eatwell } \\
\text { Alimentarse } \\
\text { correctamente } \\
\text { Comida basura } \\
\text { La cronodieta } \\
\text { Nuevo decreto en } \\
\text { Murcia } \\
\text { Obesidad y diabetes } \\
\text { Menos peso mejor } \\
\text { salud } \\
\text { Juego interactivo } \\
\text { Cafeína y salud } \\
\text { Comida basura en } \\
\text { los colegios } \\
\text { Salud dental } \\
\text { Productos de } \\
\text { temporada } \\
\text { La mejor merienda } \\
\text { Calorías en la oficina }\end{array}$ & $\begin{array}{l}\text { La pasta no } \\
\text { engorda } 2^{0} \text { Foro de } \\
\text { Estilo de Vida } \\
\text { Saludable } \\
\text { Un plato saludable } \\
\text { desde Harvard } \\
\text { Raciones } \\
\text { recomendadas } \\
\text { Lávate las manos } \\
\text { Tirando a } \\
\text { malo7/11/2012 } \\
\text { El café y la diabetes } \\
\text { Embutidos más } \\
\text { sanos } \\
\text { Regulación } \\
\text { intestinal } \\
\text { Proteína en la dieta } \\
\text { infantil } \\
\text { Dieta mediterránea: } \\
\text { patrimonio de la } \\
\text { Humanidad } \\
\text { Aumentar el apetito } \\
\text { Alergias } \\
\text { alimentarias } \\
\text { Dieta de perros } \\
\text { Proyecto Brafo } \\
\text { Alimenta tu corazón } \\
\text { Comer bien en } \\
\text { tiempo de crisis } \\
\text { Asma y dieta } \\
\text { mediterránea } \\
\text { Toxoplasmosis } \\
\text { Encuesta nutrición } \\
\text { Lácteos e } \\
\text { hipertensión } \\
\text { Comer bien } \\
\text { Desayuno saludable } \\
\text { Alimentación para } \\
\text { deportistas } \\
\text { Hipertensión y } \\
\text { nutrición } \\
\text { Plan "Cuídate más" }\end{array}$ & $\begin{array}{l}\text { Guía de nutrición } \\
\text { Alimentación y } \\
\text { ejercicio } 12 / 11 / 11 \\
\text { Programa Original } \\
\text { Flavours } \\
\text { Alergias pediátricas } \\
\text { Dieta mediterránea } \\
\text { y fertilidad } \\
\text { Comer bien } \\
\text { Alimentos para } \\
\text { celiacos } \\
\text { Excesos del fin de } \\
\text { semana } \\
\text { Malos hábitos en el } \\
\text { trabajo } \\
\text { Dieta nórdica } \\
\text { Necesidad de beber } \\
\text { Síndrome } \\
\text { metabólico } \\
\text { Blog escolar } \\
\text { Acciones de la } \\
\text { AESAN: prevenir la } \\
\text { obesidad infantil } \\
\text { Identificar alergia } \\
\text { alimentaria } \\
\text { Observatorio de la } \\
\text { obesidad } \\
\text { Hidratación } \\
\text { Dieta mediterránea: } \\
\text { nuevas ventajas } \\
\text { Dieta y colesterol }\end{array}$ \\
\hline
\end{tabular}




\begin{tabular}{|c|c|c|c|}
\hline $\begin{array}{l}\text { GRUPO 5: } \\
\text { SEGURIDAD } \\
\text { ALIMENTARIA Y } \\
\text { TECNOLOGÍA DE } \\
\text { LOS ALIMENTOS } \\
\text { (79 } \\
\text { quesitos,21,5\% } \\
\text { del total de los } \\
\text { emitidos) }\end{array}$ & $\begin{array}{l}\text { Ovoproductos } \\
\text { Alimentos } \\
\text { contaminantes } \\
\text { Nueva generación } \\
\text { de los códigos de } \\
\text { barras } \\
\text { Envases } \\
\text { autocalentables } \\
\text { Cumbre Mundial de } \\
\text { Seguridad } \\
\text { Alimentaria } 14 \text { y 15/05/11 } \\
\text { La Liofilización } \\
\text { La cadena del frío y } \\
\text { el pescado } \\
\text { Calidad diferenciada } \\
\text { en los alimentos } \\
\text { Nanotecnología y } \\
\text { seguridad } \\
\text { alimentaria } \\
\text { Nuevos envases de } \\
\text { alimentos } \\
\text { Falsificaciones } \\
\text { alimentarias } \\
\text { Nuevo panel } \\
\text { nutricional } \\
\text { La letra Q } \\
\text { Liofilización } \\
\text { Etiquetas de los } \\
\text { alimentos } \\
\text { Toxiinfecciones } \\
\text { frecuentes } \\
\text { Evitar toxinfecciones } \\
\text { Envases del futuro } \\
\text { Listeria } \\
\text { Nuevo etiquetado } \\
\text { nutricional } \\
\text { Acuerdo sobre } \\
\text { seguridad } \\
\text { alimentaria } \\
\text { Nueva base datos } \\
\text { alimentos } \\
\text { Aditivos y } \\
\text { congelados } \\
\text { Radioactividad y } \\
\text { alimentos } \\
\text { Etiqueta de jamón } \\
\text { Seguridad } \\
\text { alimentaria I } \\
\text { Seguridad } \\
\text { alimentaria II } \\
\text { Alerta E. Coli }\end{array}$ & $\begin{array}{l}\text { Peligros del } \\
\text { estropajo }{ }^{* 10 / 07 / 2011} \\
\text { Mercadillos } \\
\text { veraniegos } \\
\text { Pasteur }{ }^{* 09 / 01 / 2013} \\
\text { Papas antiguas de } \\
\text { Canarias } \\
\text { Microorganismos y } \\
\text { alimentos } \\
\text { Carne de caballo } \\
\text { Nutrigenómica } \\
\text { La Nutrigenómica } \\
\text { Condimentos de } \\
\text { origen }{ }^{* 18 / 02 / 13} \\
\text { Bollería industrial } \\
\text { con menos grasas } \\
\text { trans } \\
\text { Maduración del } \\
\text { queso } \\
\text { Etiquetado del } \\
\text { pescado } \\
\text { Etiquetado alérgicos } \\
\text { Tintas inteligentes } \\
\text { Alimentos } \\
\text { innovadores } \\
\text { Clonar leche } \\
\text { humana } \\
\text { Infecciones } \\
\text { alimentarias } \\
\text { Mayonesa } \\
\text { Recubrimientos } \\
\text { comestibles }{ }^{* 11 / 09 / 11} \\
\text { Nanoenvases } \\
\text { Higiene de los } \\
\text { alimentos } \\
\text { Nueva normativa } \\
\text { sobre chucherías } \\
\text { Nitratos en la } \\
\text { infancia } \\
\text { Prioridad industria } \\
\text { alimentaria } \\
\text { Alimentos } \\
\text { artesanales }\end{array}$ & $\begin{array}{l}\text { Seguridad cuarta } \\
\text { gama } \\
\text { Sandwich que no } \\
\text { caduca } \\
\text { Patógenos en la } \\
\text { nevera } 03 / 03 / 12 \\
\text { Congelar, sí o no } \\
\text { Cartón y toxicidad } \\
\text { Jamón ibérico } \\
\text { garantizado } \\
\text { Alimentos de otros } \\
\text { países } \\
\text { Tipos de plástico } \\
\text { Salmonella } 30 / 06 / 12 \\
\text { Nuevas tecnologías } \\
\text { alimentarias Letra } \\
\text { Q } \\
\text { A vueltas con las } \\
\text { grasas trans } \\
\text { Lista autorizada de } \\
\text { aromatizantes } \\
\text { Comida caducada } \\
\text { barata } \\
\text { Enlatados } \\
\text { Polémicos ibéricos } \\
\text { Papas antiguas de } \\
\text { Canarias } \\
\text { Guía de gestión de } \\
\text { alérgenos } \\
\text { alimentarios Horno } \\
\text { microondas } \\
\text { Prev/04/13 } \\
\text { tartera } \\
\text { Microondas con la } \\
\text { Foodomica } \\
\text { Anisakis en España } \\
\text { Cocinar al vapor } \\
\text { Enlatados }\end{array}$ \\
\hline
\end{tabular}




\begin{tabular}{|c|c|c|c|}
\hline $\begin{array}{l}\text { GRUPO 6: } \\
\text { ALIMENTACIÓN } \\
\text { SANA Y } \\
\text { ECOLÓGICA (28 } \\
\text { quesitos, 7,6\% del } \\
\text { total de los } \\
\text { emitidos) }\end{array}$ & $\begin{array}{l}\text { Ganadería biológica } \\
\text { La agricultura } \\
\text { biológica } \\
\text { Residuos químicos } \\
\text { en los alimentos } \\
\text { Alimentos } \\
\text { transgénicos } \\
\text { Plomo en los } \\
\text { alimentos } \\
\text { Hábitos alimentarios } \\
\text { en Valencia } \\
\text { Alimentos ecológicos } \\
\text { cuestionados } \\
\text { Nuevo logo } \\
\text { productos ecológicos } \\
\text { Kilómetro Cero } \\
\text { Pienso para cerdos } \\
\text { saludables }\end{array}$ & $\begin{array}{l}\text { Aroma } \\
\text { Dioxinas en } \\
\text { Alemania } \\
\text { Medidas 'post' } \\
\text { Fukushima } \\
\text { El Yodo } \\
\text { Maíz y transgénicos } \\
\text { Aditivos } \\
\text { Spray antitóxicos } \\
\text { Aluminio } \\
\text { Furanos } \\
\text { Bisfenol A } \\
\text { El colorante de los } \\
\text { refrescos de cola } \\
\text { Acuicultura } \\
\text { ecológica }\end{array}$ & $\begin{array}{l}\text { Leche modificada } \\
\text { ¿Alimentos } \\
\text { orgánicos o } \\
\text { convencionales? } \\
\text { Pesticidas } \\
\text { Biocultura } \\
\text { Golosinas e } \\
\text { investigación } \\
\text { 'Hogar sin tóxicos' }\end{array}$ \\
\hline
\end{tabular}

Respecto a las características que reúne el discurso radiofónico de las cápsulas temáticas analizadas, se trata de una exposición breve y clara, con un dominio del lenguaje sencillo que facilita la comprensión del mensaje por parte del oyente y la eficacia de la comunicación radiofónica (Legorburu, 2001: 198-200).

Aunque en algunas materias la utilización de un lenguaje técnico podía dificultar su comprensión, de acuerdo con lo que señalan Huertas y Gutiérrez (2006: 59) al ocuparse de la difusión de los temas sanitarios a través de la radio, se explican los conceptos y los tecnicismos ("HDL el conocido como colesterol bueno").

Con el objeto de propiciar un mayor acercamiento al radioyente (Díaz, 2004: 46), se logra mediante la expectación captar la atención desde el primer momento ("Vamos a prestar atención a un nuevo pescado que viene del pacífico y promete hacerse un hueco en nuestro mercado en no mucho tiempo"). A medida que avanzaba en su intervención, Teo Sánchez (Comunicación personal, 13 de mayo de 2014) hacía uso de recursos como los refranes populares y la continua apelación al oyente haciéndolo participe y captando su atención ("Recuerden", "Insisto", "Atención" o "Fíjense"), ponía un especial énfasis en las palabras claves del discurso radiofónico y empleaba ráfagas musicales para separar las ideas y lograr una mejor estructuración del discurso con el fin de que no resultase tan denso.

Además cabe destacar el uso de una única base musical sin letra en todos los programas, que ayudaba a la identificación del espacio radiofónico y al mismo tiempo evitaba que el oyente se distrajese de lo realmente importante. También cabe subrayar el uso de recursos que pudieran ayudar a fidelizarlo, como ocurre con la continuidad que se establecía entre algunos programas ("Hoy vamos a continuar con nuestra breve historia de la seguridad alimentaria y vamos a hacerlo en el punto en el que lo dejamos ayer").

La duración de los mini-espacios analizados oscilaba entre 2 y 5 minutos, siendo la franja de entre 3 y 4 minutos la de mayor frecuencia con un $82,8 \%$.

El feedback con la audiencia resulta necesario para conocer el impacto que los programas generan en la población (López Nomdedeu, Lobato, s.f.; 6; Huertas, 
Gutiérrez, 2006: 62; Sánchez Martos, 2008: 83), las redes sociales juegan un papel clave en esta materia. Por ello, Teo Sánchez (Comunicación personal, 13 de mayo de 2014) explica que el espacio contaba con varios perfiles en las redes sociales, además de un correo electrónico a disposición de los oyentes.

\section{Conclusiones}

La experiencia divulgativa de Radio 5 Todo Noticias sobre alimentación y nutrición y en concreto su espacio radiofónico 'Alimento y salud', muestran el interés y las posibilidades que ofrece la radio pública para cumplir con su función educativa y transmitir unos contenidos fiables y rigurosos, adaptados al público general, y que puedan ayudar a mejorar los hábitos alimentarios y la salud de la población.

Respecto a las recomendaciones y las posibles líneas futuras de investigación que se derivan de los resultados obtenidos, parece oportuno destacar la necesidad de seguir profundizando en la colaboración entre los profesionales del periodismo y del ámbito sanitario, que permitan optimizar las posibilidades que ofrece el medio radiofónico en el campo de la educación para la salud.

Así mismo, sería interesante establecer un análisis comparativo entre la fórmula de las cápsulas informativas o quesitos que se utilizó hasta mayo de 2013, y el formato de programa de treinta minutos de duración con el que se reiniciaron las emisiones de 'Alimento y salud' en octubre de ese mismo año.

Con el objeto de poder mejorar actividades de comunicación para la salud como las que se han llevado a cabo desde Radio 5 Todo Noticias, convendría ampliar la metodología utilizada e intentar identificar, con carácter previo, los problemas de salud que preocupan a la población y en concreto, los relacionados con la alimentación y la nutrición. También parece oportuno establecer mecanismos de evaluación y mejorar los canales y los mecanismos de retroalimentación a fin de asegurar la comprensibilidad del mensaje emitido y evitar que el oyente se convierta en receptor pasivo del mismo.

\section{Referencias}

Alonso, Sergio (2008). La información sobre la salud en la prensa general. En Cuesta Cambra, Ubaldo, Ugarte Iturrizaga, Aitor y Menéndez Hevia, Tania (eds.). Comunicación y salud: avances en modelos y estrategias de intervención. Madrid. Editorial Complutense, pp. 73-75.

Alzate Narváez, Teresa (2013). Consejos dietéticos y nutricionales en la prensa española. RevEspCom Salud. № 4(1), pp. 17-26.

Camacho, Idoia; Peñafiel, Carmen y Ronco, Milagros. (2012). Necesidad de una información sanitaria de calidad: análisis de las noticias sobre salud en la prensa vasca. En Actas del III Congreso Internacional de la Asociación Española de Investigación de la Comunicación AE-IC "Comunicación y Riesgo". Tarragona. Asociación Española de Investigación de la Comunicación (AE-IC), pp. 1-20.

Chomón Serna, José María (2010). Radio 5: del todo a la nada en la información autonómica. Ámbitos. № 19, pp. 199-216.

Chomón Serna, José María. (2011). La información de proximidad en la radio 
pública estatal: las transformaciones de Radio 5. (Tesis doctoral, Universidad de Burgos). Recuperado de http://dspace.ubu.es:8080/tesis/bitstream/10259/159/1/Chom\%C3\%B3n Serna. pdf

Cuesta Cambra, Ubaldo; Ugarte Iturrizaga, Aitor y Menéndez Hevia, Tania (eds.) (2008). Comunicación y salud: avances en modelos y estrategias de intervención. Madrid. Editorial Complutense.

De Semir, Vladimir (2003). Medios de comunicación y cultura científica. Quark: Ciencia, medicina, comunicación y cultura. № 28.29, pp. 1-13.

Díaz, Enrique José (2004). La radio y el multimedia, dos alternativas para la divulgación científica. Quark: Ciencia, medicina, comunicación y cultura. № 34, pp. 40-49.

Díaz, Hernán y Uranga, Washington. (2011). Comunicación para la salud en clave cultural y comunitaria. Revista de Comunicación y Salud. № 1(1), pp. 113-124.

Gómez, Oscar (2002). La divulgación científica en el medio radiofónico: algunos apuntes. Mediatika. № 8, pp. 59-68.

González Conde, Julia (2000). Información Universitaria en la radio pública. Radio 5-Todo Noticias. (Tesis doctoral, Universidad Complutense de Madrid). Recuperado de http://biblioteca.ucm.es/tesis/19972000/S/3/S3030301.pdf

González Huesa, José Manuel (2008). Introducción: El arte de lo imposible. En Cuesta Cambra, Ubaldo; Ugarte Iturrizaga, Aitor y Menéndez Hevia, Tania (eds.). Comunicación y salud: avances en modelos y estrategias de intervención. Madrid. Editorial Complutense, pp. 12-16.

González Huesa, José Manuel (2008). La salud de la información. En Cuesta Cambra, Ubaldo; Ugarte Iturrizaga, Aitor y Menéndez Hevia, Tania (eds.). Comunicación y salud: avances en modelos y estrategias de intervención. Madrid. Editorial Complutense, pp. 69-72.

Huertas, Amparo y Gutierrez, María (2006). Salud y radio: análisis de la práctica periodística. Quaderns del CAC. № 26, pp. 51-63.

LegorburuHortelano, JoséMaría (2001). Utilidad y eficacia de la comunicación radiofónica en el proceso educativo. (Tesis doctoral, Universidad Complutense de Madrid). Recuperado dehttp://biblioteca.ucm.es/tesis/inf/ucm-t25240.pdf

López Nomdedeu, Consuelo y Lobato, Amparo (s.f.). La necesidad de una buena comunicación sobre nutrición y salud: evolución de la imagen del huevo. Biblioteca del Instituto del Huevo (artículos), pp. 1-20. Recuperado de http://www.institutohuevo.com/images/archivos/articulo comunicacion huevo07 13132148.pdf

López Nomdedeu, Consuelo (2012). La educación nutricional en la prevención y promoción de la salud. En Carbajal Azcona, Angeles y Martínez Roldán, 
Cristina (eds.). Manual Práctico de Nutrición y Salud Kellogg's. Madrid. Exlibris, pp. 95-108.

Martín Algarra, Manuel. (2008). Comunicar la salud: Análisis comparativo de dos campañas de comunicación para la salud realizadas en Galicia en los años noventa. En Cuesta Cambra, Ubaldo; Ugarte Iturrizaga, Aitor y Menéndez Hevia, Tania (eds.). Comunicación y salud: avances en modelos y estrategias de intervención. Madrid. Editorial Complutense, pp. 155-167.

Menéndez Hevia, Tania (2008). Prólogo. En Cuesta Cambra, Ubaldo; Ugarte Iturrizaga, Aitor y Menéndez Hevia, Tania (eds.). Comunicación y salud: avances en modelos y estrategias de intervención. Madrid. Editorial Complutense, pp. 9-10.

Moreno, Elsa (2005). Las "radios" y los modelos de programación radiofónica. Comunicación y Sociedad. № 18(1), pp. 61-111.

Perelló, Salvador y Muela, Clara (2011). An Analysis of Health-Related Advertising in Spanish Radio. Cuadernos de información. № 29, pp. 67-76.

Presentación de la Encuesta Nacional de Ingesta Dietética Española (ENIDE). Agencia española de Seguridad Alimentaria. [Acceso 11de octubre d 2014]. Disponible en: http://aesan.msssi.gob.es/AESAN/docs/docs/notas prensa/Presentacion ENID E.pdf

Revuelta, Gemma (2006). Salud y medios de comunicación en España. GacSanit. № 20(Supl1), pp. 203-208.

Rodero, Emma (2008). Educar a través de la radio. Signo y Pensamiento. № 52, pp. 97-109.

Roldán Vera, Eugenia (2009).Los orígenes de la radio educativa en México y Alemania: 1924-1935. Revista Mexicana de Investigación Educativa. № 40, pp. 14-17.

Sánchez Martos, Jesús (2008). Influencia de los medios de comunicación en la salud de la población. En Cuesta Cambra, Ubaldo; Ugarte Iturrizaga, Aitor y Menéndez Hevia, Tania (eds.). Comunicación y salud: avances en modelos y estrategias de intervención. Madrid. Editorial Complutense, 77-97.

Trescastro López, Eva María, Bernabeu Peiró, Àngela (coord.) (2015). Aprender a comer saludablemente a través de la radio. Guía para educadores. Alicante. Publicacions de la Universitat d'Alacant.

Ugarte Iturrizaga, A. (2008). El binomio comunicación y salud: Relaciones e investigación. En Cuesta Cambra, Ubaldo; Ugarte Iturrizaga, Aitor y Menéndez Hevia, Tania (eds.). Comunicación y salud: avances en modelos y estrategias de intervención. Madrid. Editorial Complutense, pp. 39-47. 
Varela Moreiras, Gregorio (ed.). (2013). Libro Blanco de la Nutrición en España. Madrid. Fundación Española de Nutrición/ Agencia Española de Seguridad limentaria y Nutrición. 